\title{
La figura imperial femenina en época tardorromana a través de Zósimo y el CTh.
}

\author{
José Luis Cañizar Palacios \\ Universidad de Cádiz
}

\begin{abstract}
RESUMEN:
Con el presente trabajo se pretende profundizar en la consideración de

las mujeres del entorno de los emperadores tardorromanos de la cuarta centuria. Para ello se analizan las alusiones que a ellas se realizan en dos trascendentales obras para el contexto histórico del siglo IV d.C. como son las incluidas en la del escritor pagano Zósimo y en la compilación teodosiana. Con su análisis se intenta reivindicar el protagonismo femenino en la dirección de los asuntos del Estado si bien sea cierto que oficialmente en esta, como en tantas otras cuestiones, la mujer resulte
\end{abstract}
ABSTRACT:
With the following work we aspire to go deeply into the consideration of the women in the emperors' circle of the 4th century in Late Antiquity. In this sense we analyse the references formulated about them in two determinants books for the historic context of this age, like the New Historian of the pagan writer Zosimo and the Theodosian Code. With their analysis we aspire to vindicate the female's high profile in the management of the State's affairs although it's true that officially in this aspect, like in others questions, women are ignored.

ignorada.

En el presente trabajo pretendemos confrontar las noticias que, sobre la mujer perteneciente a la casa imperial, hallamos de una parte en la obra del historiador pagano Zósimo, y de otra en un documento oficial del Estado tardorromano como es la compilación de leyes auspiciada por Teodosio II y que conocemos como Código Teodosiano. Se trata de dos fuentes de información de capital importancia para el contexto histórico del siglo IV d.C. dado que, de un lado la Nueva Historia de Zósimo se ocupa fundamentalmente de los acontecimientos que tienen su desarrollo en ese periodo de tiempo, extendiéndose hasta los inicios del siglo $\mathrm{V}$ d.C., y que de otro la legislación del Teodosiano principia en el año 312 (CTh.XI,29,1 del 27 de diciembre de ese año) y concluye en la década de los años 30 de la quinta centuria (CTh.Vl,23,4 del 16 de marzo del 437). 
Una y otra fuente de información nos van a permitir una mayor y mejor valoración de la mujer tardoantigua, especialmente de aquella perteneciente a la familia y la casa imperial, objeto de estudio del presente artículo, por cuanto su consideración y dignidad pública la faculta en la práctica, aunque no en la teoría, para la participación en la política y gobierno de la época y de ahi que resulten frecuentemente aludidas en la obra de Zósimo'. Recordemos que, como sucedía con cualquier otra mujer romana, la integrante de la familia imperial estaba apartada de las tareas de gobierno, excluida de los órganos de poder e incapacitada, por su condición sexual, para el desempeño de funciones públicas ${ }^{2}$. En la práctica, sin embargo, tal y como afirmamos, y especialmente en el caso concreto de la emperatriz y más exactamente en el de aquella poseedora del rango de Augusta, la mujer también participa del poder del emperador aunque teóricamente no ejerza ni detente poder alguno, si bien su influencia pueda resultar determinante por cuanto es su esposa y madre de su futura descendencia, es decir, madre de futuros emperadores.

En primer lugar hemos de identificar las referencias que en una y otra obra poseemos sobre el asunto en cuestión. En el caso de Zósimo, son varias sus alusiones directas a miembros femeninos de la familia imperial, siendo más numerosas las referencias a las mujeres vinculadas con la dinastía constantiniana. De este modo son citadas la madre, la hermana, la primera y segunda esposa y las hijas de Constantino, es decir, y por este orden, Helena, Constancia, Minervina, Fausta, Constantina y Helena. Al mar-

Sobre el particular, CLARK, G. (Women in Late Antiquity. Pagan and Christian lifestyles, New York $1993,139-140$ ) concluye que efectivamente el status público resulta inadecuado para las mujeres a menos que sean miembros de la casa imperial, precisando que incluso en tales circunstancias se esperará de ellas que se adecuen al estilo de vida apreciado y valorado tradicionalmente en la mujer de familia romana, esto es, que cobren vida en ellas virtudes como la modestia, la castidad y la piedad hacia los dioses y la familia, dado que la finalidad de sus vidas, como la de cualquier otra mujer, es el matrimonio, la procreación y la crianza de su prole.

2 Ulpiano I,3,31.

Por supuesto también en el Teodosiano es posible encontrar muestras de este secundario y marginal papel jugado por la mujer. Asi sucede por ejemplo en tres constituciones de Teodosio I: CTh.XVI,2,28 del 23 de agosto del 390 , donde se define a la mujer como el "infirmis sexus"; CTh.11,1,7 del 10 de noviembre del 392 donde al afirmarse que "ensalzamos a las mujeres de acuerdo con el honor de sus maridos, las ennoblecemos según las familias de éstos", se hace depender el respeto a la figura temenina del grado y dignidad del esposo al tiempo que se hace hincapie en su condición de ser inferior (Ja lectura positiva de la ley, es que la mujer puede detentar idéntico rango que el hombre); y CTh.Il,12,5 del 28 de septiembre del 393, donde se indica que las mujeres no pueden conducir por si mismas asuntos legales más allá de lo estipulado en la ley, es decir, por encima de lo que en ella se les reconozca.

Cierto es, pese a todo, que en la misma compilación se deja entrever un cambio en la estimación de la figura femenina, y asi sucede que en CTh.VI,4,17 del 19 de enero del 370 , la mujer comienza a ser considerada para la herencia de los deberes y obligaciones de los senadores cuando éstos fallecen sin descendencia masculina. No obstante puede igualmente pensarse que el objeto final de la ley es que el Estado se asegure el cumplimiento de los deberes senatoriales y lo que ello supone económicamente.

Acerca de la valoración de la mujer en la legislación tardoimperial, vid. BISCARDI, A., “Spose, madri, nubili, vedove: echi patristici nella legislazione tardo-imperiale», Atti dell'Accademia Romanistica Constantiniana, VII! Convegno Internazionale, Perugia 1990, 325-334, donde se concluye que la consideración de la mujer en la legislación tardorromana es altísima, fruto especialmente de la influencia cristiana y de la Iglesia, estimando que ya en los escritos de los Padres de la Iglesia existe una equiparación entre la esposa y el marido. 
gen de ellas, también hallamos en la obra de Zósimo una alusión a una tal Eutropia de la que se dirá que era también hija suya $(Z o s .11,43,2)$, y, sin abandonar esta dinastía, se alude también a Eusebia, la esposa de Constancio II.

En relación con la dinastía valentiniana, son nombradas Justina, esposa de Valentiniano I, su fundador, y Gala, su hija. Por último ligadas a la familia de Teodosio I, son citadas además de ésta última, su primera esposa Flaccila, su hija Gala Placidia, su sobrina Serena, y las hijas de ésta Maria y Termancia ${ }^{3}$.

Pues bien, del estudio de los pasajes en los que resultan mencionados estos miembros femeninos de la domus imperial, se derivan varias conclusiones que, por otra parte, sirven de complemento a la imagen que de ellos nos transmite el corpus jurídico de Teodosio II, aunque en este último caso se sea parco en detalles. Asi apenas podemos citar un par de constituciones en las que se mencionen directamente a mujeres de la casa imperial. Concretamente hablamos de CTh.IX,38,1 fechada el 30 de octubre del 322 y donde se alude a la esposa de Crispo, de nombre Helena, y CTh.XIII,1,21, datada el 21 de agosto del 418 y donde se cita a Pulqueria, hermana mayor de Teodosio $11^{4}$. A ellas habría que sumar una alusión indirecta en CTh.X,25,1 a tres de las hijas que Arcadio tuvo de su matrimonio con Eudoxia: Pulqueria, Arcadia y Marina (las dos últimas igualmente mencionadas de forma indirecta en CTh.XIII, 1,21) .

Una vez precisadas las citas al tema en cuestión en la obra de Zósimo y en la compilación teodosiana, es el momento de analizar sus contenidos. El primer dato llamativo es la escasez de noticias sobre las féminas de la casa imperial en la legislación, lo cual viene a corroborar su escaso peso especifico, desde el punto de vista institucional, en el seno del Estado tardorromano. Sumemos a lo dicho que, con independencia del número de leyes en las que se las alude, ni en la inscriptio ni en la subscriptio de las constituciones

${ }^{3}$ Sorprende en la Nueva Historia la ausencia de alusiones sobre la mujer del emperador Arcadio y madre de Pulqueria, Aelia Eudoxia, entre otras razones porque detentó el rango de Augusta, dignídad a la que resultó elevada en enero del año 400 y que distrutó hasta su muerte en octubre del 404 (vid. PLRE vol. II, 410). Sumemos a lo dicho que se ha resaltado igualmente su protagonismo durante el reinado del mencionado emperador, circunstancia por la que resulta aún más llamativa la omisión de su nombre (HOLUM, KENNETH G., Theodosian Empresses. Women and Imperial Dominion in Late Antiquity, Univ. California, Berkeley-Los Angeles-London 1982, 48 y ss.)

4 En la primera de ellas (CTh.IX,38,1) con motivo del nacimiento de un nieto de Constantino, fruto del matrimonio de su primogénito Crispo con Helena, se ordena un indulto para todos los criminales a excepción de envenenadores, homicidas y adúlteros. En la segunda (CTn.XIII,1,21) se dispone el pago de la lustralis conlatio por parte del personal de la domus de las hermanas del emperador Teodosio II.

5 Exactamente en el texto de la constitución imperial atribuida al emperador Arcadio se habla de "nobilissimae puellae filiae", detallándose, en el comentario que a la ley realiza Gothofredus, que en efecto se trata de las mencionadas Pulqueria, Arcadia y Marina (Codex Theodosianus cum perpetuis commentariis lacobi Gothofredi, vol. III, Lipsiae 1736, 562-563).

Respecto al título de "nobilissimus", recordemos que es de uso habitual entre los miembros de la familia imperial, siendo empleado desde fines del s. Il d.C. en referencia al Caesar (MAGIONCALDA, A., Lo sviluppo della titolatura imperiale da Augusto a Giustiniano attraverso le testimonianze epigrafiche, Torino 1991, 87). 
imperiales se hace mención a ellas, lo cual acontece no sólo en la compilación teodosiana, sino también en la legislación inmediatamente posterior incluida en las Novelas ${ }^{6}$. De forma que desde el punto de vista de la ley, queda confirmado, al menos de un modo formal, que las emperatrices romanas carecieron de autoridad.

En todo caso no ha de sorprendernos la ausencia de la mujer en el encabezamiento de las leyes, ya que además de su oficialmente papel secundario ha de tenerse presente que sólo aquellos individuos con la dignidad de Augustus poseian la facultad de incluir sus nombres en la inscriptio de las constituciones y aparecer como sus emisores ${ }^{7}$, y sucede que a lo largo de la cuarta centuria únicamente alcanzaron el rango de Augusta tres féminas de la casa imperial: la madre y segunda esposa de Constantino (respectivamente Helena y Fausta) y la primera esposa de Teodosio I, Flaccila ${ }^{8}$. Con todo, ni siquiera en estos casos la legislación imperial se hace eco del protagonismo femenino a la hora de procederse a la publicación de la ley ${ }^{9}$.

No queda ahí la desigualdad entre el varón que ocupa la dignidad de Augustus y la mujer que detenta la de Augusta. Si en el primer caso ello bastaba para ser reconocido con dicha titulación en todo el Imperio, en cambio en el segundo únicamente sucedía en el ámbito de influencia del Augustus al que la mujer en cuestión estuviera asociada, dicho de otra forma, en su pars imperii ${ }^{10}$. Al respecto recordemos que durante la cuarta centuria es habitual

${ }^{6}$ En el caso de esta legislación, las constituciones conservadas se datan entre el 31 de enero del 438 (NTh.III,1) y el 19 de marzo del 468 (NAnth.III,1).

Ello no impide que sin embargo algunas de las constituciones del Teodosiano muestren en la inscriptio además del Augustus de turno, al que en aquel instante detentaba el rango de Caesar. Es el caso, por ejemplo, de numerosas leyes fechadas en el 356 y donde aparece Constancio II en calidad de Augustus y Juliano en la de Caesar: CTh.XVI,10,6;IX,23,1;IX,42,2; I,2,7; XIII,1,1; y IX,17,3. Lo mismo sucede en la legislación de los años 357, 359 y 360, con idénticos protagonistas, y en la del año 425 con Teodosio il y Valentiniano III, el primero como Augustus y el segundo como Caesar.

a Sobre la interrupción del titulo de Augusta para las mujeres de la familia imperial durante la cuarta centuria, téngase en cuenta la opinión de CAMERON A.-LONG. J. en Barbarians and Politics at the court of Arcadius, University of California 1993,170 , nota 85 , quienes consideran que son las trágicas y polémicas circunstancias que rodean a la muerte de Fausta, en aquel momento Augusta, las que lo explican. Al respecto recordemos que según Zósimo Fausta fue mandada ajusticiar por Constantino ante las sospechas de que habia mantenido relaciones sexuales con su primogénito Crispo, igualmente ajusticiado (Zos.II,29,2). Al respecto se ha señalado que la versión de Zósimo es interesada ya que con esta afirmación pretende vincular la conversión al cristianismo del emperador con los remordimientos que este asesinato le provocaría (ZUCHELLI G., "La propaganda anticonstantiniana e la falsificazione storica di Zosimo", Aspetti dell'opinione pubblica nel mondo antico. Contributi dell'Istituto di storia antica, vol. IV, Vita e Pensiero, Università Cattolica del Sacro Cuore, Milano 1976, 229-251; PASCHoud, F., "Zosime 2,29 et la version païenne de la conversion de Constantin», Historia XX (1971), 334-353).

${ }^{9}$ Por supuesto no ocurre lo mismo en otros vehículos propagandisticos del poder, como es el caso de las monedas. Asi por ejemplo Helena aparece con el rango de Augusta en monedas del 326 (por ejemplo, M.G.RIC VII, 291) tal y como aparece en la obra de ARROYo ILERA, R., Numario de la Universidad de Valencia, Universidad de Valencia 1984, 340.

10 Una excepción a esta norma no escrita, en función de las noticias aportadas por la Prosopografia, es el caso de Aelia Gala Placidia, que aunque fue desposeida de su dignidad de Augusta en la zona occidental, conservó el título mientras se refugió en el Oriente del Imperio (vid. PLRE vol. II, 889). 
la existencia de más de un Augustus al mismo tiempo ${ }^{11}$, pero siempre se les reconoce a todos tal dignidad con independencia de la zona que controlen, si bien en la práctica únicamente gobiernen en una concreta parte del Imperio $^{12}$. No sucede lo mismo con la mujer depositaria del título de Augusta.

Pese a lo dicho resulta incuestionable el protagonismo político de la mujer en el siglo IV d.C..$^{13}$, y ello queda expuesto de forma manifiesta en la obra de Zósimo. De su contenido se desprende la importancia de la política matrimonial para de un lado la legitimación en el trono (de ahí que también la practiquen los usurpadores ${ }^{14}$ ) y de otro su conservación en el seno de una misma dinastía, para lo cual resulta trascendental la descendencia, y en ello la figura femenina es determinante ${ }^{15}$. Igualmente se deriva de su obra otro dato significativo: la influencia que las mujeres del entorno de los emperadores (la madre, la esposa o la hermana por ejemplo) ejercen sobre sus decisiones, en especial cuando éstos son menores o carecen de carácter. Ello no resulta extraordinario por cuanto hablamos de personas que forman parte del círculo más próximo a la figura del emperador y que en consecuencia son de las que más pueden influir en su autoridad y proceder ${ }^{16}$. A menudo pues, el papel de las mujeres imperiales es determinante, pero como se ha

1 Así por ejemplo en el encabezamiento de la legislación tardoimperial incluida en el Teodosiano hallamos constituciones que muestran en la inscriptio "Valentinianus, Valens et Gratianus AAA.", "Theodosius, Arcadius et Honorius AAA.", "Arcadius, Honorius et Theodosius AAA.", ...

12 Cierto es, en cualquier caso que aquí también hay excepciones, como sucede con Constancio III que aunque fue proclamado Augustus por Honorio en Occidente, nunca fue reconocido como tal en la zona oriental (vid. PLRE vol. II, 321-325).

13 Como acertadamente ha destacado MARcos, M. ("Representaciones visuales del poder en época tardoantigua: la imagen de la emperatriz", Hispania Sacra 48 (1996), 513-540), la emperatriz participa del mismo lenguaje usado por el emperador para difundir una determinada imagen pública, lo cual se manifiesta de manera concreta en distintos soportes para la propaganda imperial, tales como esculturas, panegíricos, oraciones fúnebres, inscripciones, monedas, ...

14 En este sentido téngase presente que también en este terreno los usurpadores suelen imitar a los emperadores legitimos de manera que es habitual que empleen sus medios y sus técnicas propagandisticas (por ejemplo inicial rechazo del poder, el empleo de una determinada titulación, vestir el manto púrpura, el origen militar, la aclamatio, ....). Al respecto vid. Rooriguez Gervás, M.J. Propaganda política y opinión püblica en los panegiricos latinos del Bajo Imperio, Universidad de Salamanca 1991, 31-49; WARDMAN, A.E. "Usurpers and internal conflicts in the $4^{\text {th }}$ century A.D.", Historia XXXIII (1984), 226-227.

${ }^{15}$ En todo caso recordemos que el modo y forma en el que se transmitía el poder en Roma careció durante todo el imperio de un aparato legal que lo sancionase, si bien sea cierto que desde los dias de Constantino primó el principio de la hereditariedad del trono, de ahi que hablemos de dinastias constantiniana, valentiniana o teodosiana, por cuanto el poder se transmite en el seno de una misma familia.

Una buena muestra de la importancia concedida a la descendencia es que no es extraordinario encontrar emperadores tremendamente fértiles. De este modo Constantino de su unión con Fausta tuvo cinco hijos (Constantino II, Constante, Constancio II. Constantina y Heleria) a los que habria que sumar su primogénito Crispo, fruto de su unión con Minervina; por su parte Valentiniano I del matrimonio con Justina, tuvo cuatro hijos (Valentiniano II, Gala, Justa y Grata) a los que habria que añadir a Graciano, nacido de su unión con Marina Severa; Teodosio I de su matrimonio con Gala, una hija (Aelia Gala Placidia), y anteriormente tres vástagos de su matrimonio con Flaccila (Arcadio, Honorio y Pulqueria); y por último Arcadio con Aelia Eudoxia tiene cinco descendientes (Flaccila, Pulcheria, Arcadia, Teodosio Il y Marina). En total, estos cuatro emperadores suman 20 potenciales herederos.

${ }_{16}$ Desde este punto de vista su influencia es similar a la que en determinados momentos pudieron ejercer otros personajes de la corte como puedan ser los eunucos. Sobre el particular vid. HoPKINS, K., Conquistadores y esclavos, Barcelona 1981, 205-230. 
indicado no tanto como fruto de una voluntad personal por su parte, sino como "portavoces" de un grupo que las rodea y que está presto a actuar ${ }^{17}$.

Entrando en detalles, la primera alusión en la obra de Zósimo a la política matrimonial practicada por los emperadores y por los aspirantes al trono, es la que hallamos en Zos. I,39,2 en referencia al matrimonio de Constantino con Fausta, hija del Augusto Maximiano quien de este modo pretendía «persuadirlo para que persiga a Maximiano Galerio, en retirada de Italia, y conspire contra Majencio" ${ }^{18}$. Otro tanto de lo mismo aparece en Zos.II,17,2, también con Constantino como protagonista pero en esta oportunidad desposando, poco antes del Edicto de Milán del 313, a su hermana Constancia con Licinio, matrimonio en el que ambos se hallarían grandemente interesados a fin de cimentar su naciente alianza política ${ }^{19}$. Lo mismo hallamos en Zos.II,45,1, donde es ahora Constancio II quien imita a su padre (todo un experto en el uso de las mujeres de la familia imperial para alcanzar fines políticos) y otorga a su hermana Constantina en calidad de esposa a su primo Galo, recientemente nombrado Caesar ${ }^{20}$. En Zos. III,2,1 de nuevo Constancio II practica la política matrimonial desposando a su hermana Helena en esta oportunidad con Juliano, el nuevo Caesar tras la ejecución de Galo en el 354.

Ya al reinado de Teodosio I pertenecen las siguientes referencias a esta política. Así se nos informa del emparentamiento de Teodosio I con la dinastía valentiniana al desposarse, a la muerte de su primera esposa Flaccila, con Gala, hija de Valentiniano I y de Justina (Zos.IV,44,2-4) ${ }^{21}$. El mismo proceder sigue el regente de Occidente Estilicón quien en su deseo de asociarse al trono y no satisfecho con haber tomado en el 384 como esposa a

17 Sirago Vito A., L'uomo del IV secolo, Napoli 1989, 26.

is Las traducciones de la obra de Zósimo son las de José Maria Candau Morón incluidas en la edición de Biblioteca Clásica de Gredos, Madrid 1992.

19 Al respecto, vid. POhlsander Hans A., "Constantia", AncSoc 24 (1993), 151-167. En el caso de Constancia, casi con total seguridad detentaria hasta el 324 la dignidad de Augusta en la parte del Imperio regida por su esposo Licinio, fallecido en esa fecha. A partir de ese instante cesó como Augusta y pasó a ser considerada "nobilissima".

20 Prueba de la importancia de la mujer en el juego político es que la propia Constantina fue solicitada como esposa por el usurpador Magnencio con la idea de dar legitimidad a su usurpación (Chronicon Pascale 350). Por consiguiente vuelve a confirmársenos que los usurpadores suelen imitar a los legítimos emperadores.

21 Sobre el particular recordemos que Teodosio accede al poder imperial sin tener lazo familiar alguno con la casa reinante, siendo su valia en el campo de batalia to que principalmente le facultó para resultar elegido como colega en el trono por Graciano en el año 379 (en ello sin duda alguna influiria el reciente episodio del desastre militar del 378 de las tropas romanas en Hadrianopolis). En consecuencia inicialmente sería acuciante la necesidad de legitimación en el trono, más si tenemos en cuenta que anteriormente su padre, Flavio Teodosio, había sido ejecutado acusado de traición. En tal sentido se preocupará de una parte por restablecer el buen nombre y memoria de su padre, y de otra iniciará una política dinástica elevando a la categoría de Augusta a su primera esposa Flaccila. A su muerte, y continuando con esa politica de legitimación en el trono, estimará oportuno el casamiento con Gala, miembro de la dinastía valentiniana.

Acerca de las circunstancias que rodean la designación de Teodosio como Augustus, vid. WILLIAMS, S. \& FRIELL, G., Theodosius, the Empire at Bay, London 1994, 23 y ss. Sobre la recuperación del buen nombre de su padre, VERA, D., "Le statue del senato di Roma in onore di Flavio Teodosio e l'equilibrio dei poteri imperiali in età teodosiana", Athenaeum LXVII (1979), 381-403. Y finalmente sobre la política dinástica del emperador, Marcos, M., "Política dinástica en la corte de Teodosio I: las imágenes de Aelia Flavia Flaccila", Congreso Internacional La Hispania de Teodosio, Segovia 1995, Actas del volumen I, Segovia 1997, 155-164. 
Serena, sobrina e hija adoptiva de Teodosio I (Zos.IV,57,2) ${ }^{22}$, refuerza su posición al casar sucesivamente a las hijas de su matrimonio, María y Termancia, con Honorio (Zos. V,4,1; 12,1; y 28,1-3) ${ }^{23}$, Augustus occidental tras el fallecimiento de su padre Teodosio I en el 395.

A diferencia de lo que sucede en la obra de Zósimo, en el Teodosiano resulta más complicado percibir el influjo de la mujer en la política imperial y, más exactamente al tratarse de una compilación de leyes, en la composición de las constituciones dado que se encuentran incapacitadas para firmarlas, razón por la cual no aparecen nunca en sus encabezamientos. No obstante existe cierta normativa que bien pudiera deberse al empeño y esfuerzo no de los Augusti del momento, sino de las mujeres de la casa imperial. Tal sería el caso de algunas constituciones emitidas en tiempos del reinado de Valentiniano II durante la minoría de edad del emperador y que pudieran ser atribuidas a su madre Justina, de otras en los primeros instantes del mandato de Teodosio II y que pudieran adjudicarse a su hermana mayor Pulqueria, y por último de constituciones publicadas durante la minoría de edad de Valentiniano III y cuya atribución a su madre Gala Placidia tampoco sería descabellada.

En el primer caso es el propio Zósimo quien deja clara la influencia de la emperatriz y así dice de ella «Pero Justina, que no carecía ni de experiencia en los asuntos del Estado ni de recursos cuando de alcanzar una situación ventajosa se trataba ..." (Zos.IV,44,2). No le falta razón a nuestro historiador pagano por cuanto el contacto con el poder le viene de antiguo a Justina ya que fue primero esposa del usurpador Magnencio y luego de Valentiniano I. Cuando éste fallece en el 375, Valentiniano II sólo contaría con cuatro años. Todavía sería menor de edad a la muerte de su hermanastro Graciano en el 383 , quedando en aquel instante como único Augustus de la zona occidental del Imperio, de manera que durante todo ese periodo de tiempo estaría sujeto al control de su madre quien desde esta última fecha, actuaria además en calidad de regente ${ }^{24}$. En consecuencia bien pudiera pensarse que la legislación emitida en la pars Occidentis entre agosto del 383 y agosto del 388 (inicio y término de la usurpación de Magno Máximo) y teniendo en cuenta el lugar de emisión y los destinatarios de la normativa, sería obra de

22 En el caso de Estilicón, precisemos que dados sus orígenes semi-bárbaros (de padre vándalo: Orosio VII,38,1, y madre romana, vid. PLRE vol. I, 853-858), sería consciente en todo momento de la imposibilidad de ser reconocido en algún momento como legítimo emperador, pero al asociarse con la casa imperial gracias primero a su unión matrimonial con Serena, y luego al matrimonio de su hija María con el emperador Honorio, abria en cambio a su descendencia (más concretamente a su hijo Euquerio) las puertas para en el futuro acceder al trono.

23 Precisamente en esta última cita que alude a Serena (Zos. $V, 28,3$ ) se nos resume a la perfección lo que comentamos al respecto del poder e influencia de las mujeres de la corte imperial: “A todo esto murió la joven (se refiere a Maria) en ignorancia de la vida matrimonial, en vista de to cual Serena, lógicamente deseosa de descendencia imperial y ante el temor de que su considerable poder se viese disminuido, empeñó sus fuerzas en desposar a Honorio con su segunda hija (Termancia)".

24 En todo caso signifiquemos que Justina jamás llegó a detentar el rango de Augusta aunque ciertamente ello no impide que en ocasiones se conduzca como tal. 
Teodosio I, trasladado al lugar con motivo de la usurpación, del usurpador Magno Máximo o, por qué no, de la propia Justina ${ }^{25}$.

Esto último parece más claro en el caso de la redacción de CTh.XVI,1,4 del 23 de enero del 386 y publicada en Mediolanum (de hecho resulta habitual que se le atribuya su composición ${ }^{26}$ ). Por lo demás se trata de una constitución cuya inclusión en el Teodosiano llama poderosamente la atención por cuanto en ella se otorga protección al arrianismo (confesión religiosa de la que participa la emperatriz ${ }^{27}$ ), y que con posterioridad será condenado por la compilación teodosiana ${ }^{28}$.

En cuanto a la alusión en el Teodosiano a Pulqueria (CTh.XIII,1,21), se trata del único momento en el que en la compilación hallamos una completa y significativa titulación en referencia a mujeres de la casa imperial, y de este modo se dice «... nec si ad domum dominae ac venerabilis Augustae Pulcheriae germanae nostrae seu nobilissimarum sororum pietatis nostrae pertineat". En suma como vemos en esta ley atribuida a Teodosio $\|^{29}$ y publicada el 21 de agosto del 418, Pulqueria aparece descrita como Augusta, venerabilis y nobilissima. Aunque sea Teodosio II quien en teoría aparezca como emisor de la ley, no está de más traer a colación la opinión de Gothofredus para quien en aquel momento el emperador sería menor de edad, con lo cual bien pudiera actuar la propia Pulqueria como regente de la pars Orientis y en consecuencia erigirse en la auténtica emisora de la constitución, en cuyo caso con esta directa alusión se estarían reivindicando su protagonismo y dignidad en el Estado ${ }^{30}$.

25 En este sentido se expresa JoNES, A.H.M. en The Later Roman Empire, Oxford 1973, 341, afirmando que fue Justina la virtual gobernante de la zona occidental en el periodo que va desde el asesinato de Graciano en el 383 a su propia muerte en el 388 . Desde este punto de vista pudiera deberse a su persona la publicación de una amplia normativa surgida en ese tiempo en la zona occidental del imperio: CTh.Xill, 1,$2 ; \mid X, 38,7 ;$ VI,5,2; VI,30,6; IV,17,4; XI,30,44 y XII,1,107 del 384; y CTh.XVI,1,4; XIII,5,17; X,13,1; XIV,1,2; XIV,3,18; VI,35,13; VIII,7,18; XII,1,113; XI,1,22;II,8,18; VIII,8,3; XI,7,13; XI,37,1; y VIII,8,4 del 386. En cualquier caso sería necesario un estudio más pormenorizado de la inscriptio y subscriptio de toda esta legislación para definitivamente confirmar la posible autoría de Justina

26 Tal es el caso por ejemplo de GoTHOFREDUs en el comentario que a la constitución formula en su magna obra (op.cit., vol. VI, $1 / \mathrm{V}, 2,109-110$ ). Al respecto signifiquemos que con la misma datación, esto es, el 23 de enero del 386, y con idéntica temática (defensa del arrianismo) aparece en la compilación teodosiana CTh.XVI,4,1 publicada en Constantinopolis. Sería en principio una de las extrañas muestras de simultaneidad en la publicación de la ley en ambas partes imperii, si bien según Gothofredus hay un error en la subscriptio y el lugar de publicación sería nuevamente Mediolanum. En cualquier caso no le cabe duda alguna de que en ambas casos (CTh.XVI,1,4 y 4,1) se trata de legislación impulsada por Justina.

${ }_{27}$ Al respecto, vid. PLRE vol. I, 488-489.

28 En concreto se trata de CTh.XVI,5,60 y 65 de los años 423 y 428 , donde se prohíbe a los arrianos la posesión de Iglesias en el Imperio.

29 Aunque en la inscriptio de la ley aparezcan como emisores Honorio y Teodosio II, dado que el destinatario es el prefecto del pretorio Monaxius, funcionario de la zona oriental del Imperio (vid. PLRE vol. II, 545), hemos de pensar en la atribución de la ley a la cancillería imperial de Teodosio II.

30 Según la Prosopografía, Teodosio II habría nacido en el año 401, siendo proclamado Augustus el 10 de enero del 402 (PLRE vol. II, 1100), con lo cual en el momento de la publicación de la constitución efectivamente seria menor de edad y pudiera tenerse en consideración la opinión de GotHOFREDUS en el comentario realizado a la ley (op.cit., vol. V, 22-23). Por su parte Pulqueria tendria únicamente dos años más que su hermano, pese a lo cual ejercería una poderosa infiuencia sobre él incluso tras que éste alcanzase su mayoria de edad (PLRE vol. II,929-930; LIPPOLD, "Theodosius II», REL 13, München 1973, 966). 
Recordemos que a la muerte de su padre Arcadio en el 408, actúan como regentes funcionarios del consistorio imperial, tales como el prefecto del pretorio Anthemius ${ }^{31}$, y que Pulqueria fue elevada a la dignidad de Augusta en el 414, cuando contaba con 15 años, momento a partir del cual es ella la regente de la zona oriental. En todo caso cierto es que no queda claro quién verdaderamente es el responsable de la normativa imperial durante la minoría de edad de Teodosio ||$^{32}$.

De otro lado signifiquemos que el caso de Teodosio II representa un claro ejemplo de emperador de débil carácter puesto que con posterioridad se dejará sentir sobre su persona la influencia de otra mujer, Aelia Flavia Eudocia, con la que se desposa siguiendo el consejo de su hermana Pulqueria. Más aún, se ha señalado que diversas leyes promulgadas en el 425 y alusivas a la ciudad de Constantinopolis se deben a la influencia de la consorte del emperador ${ }^{33}$, quien además poseyó el título de Augusta prácticamente desde su unión matrimonial en enero del 423 hasta su muerte en octubre del $460^{34}$. En consecuencia y dado que Pulqueria posee igualmente dicha titulación desde el 414 , vemos cómo en la zona oriental del Imperio conviven dos Augustae entre esa fecha y el 453 (muerte de Pulqueria). Pues bien, ni una ni otra aparecen en la inscriptio de las leyes imperiales, en una muestra más de la diferente consideración que a nivel oficial se tiene de las figuras imperiales masculina y femenina.

En similares circunstancias a las de Valentiniano II y Teodosio II se haIla la legislación atribuida a Valentiniano III durante su minoria de edad y que pudiera deberse a la mano de su madre Gala Placidia, hermanastra de Arcadio y Honorio, esposa de Constancio III y que como sus contemporáneas Pulqueria y Aelia Flavia Eudocia detentó el rango de Augusta. No obstante señalemos que al parecer a la muerte de su esposo Cons-

3t En este sentido se expresa JONES, A.H.M. (op.cit., 179).

32 Al respecto se ha destacado que Pulqueria utilizó su condición de Augusta para cambiar el curso de la Historia y que como su madre Eudoxia, en la práctica ejerció el poder real (HOLUM, KENNETH G., op.cit., 79 y 111). Igualmente se ha señalado que ciertamente resulta algo aventurado reconstruir las relaciones familiares de Teodosio II y sus hermanas en los primeros años de su reinado, si bien puede asumirse que fue Pulqueria quien actuó de árbitro e impuso su autoridad, convirtiéndose en guardiana de los intereses de su hermano (HOLUM, KENNETH G., op.cit., 90-91). De otra parte a partir de la información contenida en las obras de historiadores como Sozomeno y Sócrates, puede afirmarse que existe cierta continuidad entre la noción de basileia que Pulqueria impuso en sus hermanas, y la advertida anteriormente en Flaccila y Eudoxia, con la salvedad que en el caso de Pulqueria se decantará por mantener la virginidad y la castidad en función de sus convicciones religiosas. Pese a ello, tras la muerte de Teodosio ll en el 450 , y en una prueba más de la práctica de la política matrimonial, se unió en matrimonio con Marciano, quien carecia de vínculos familiares con la casa teodosiana.

33 En tal sentido se expresa DE GıovanNi, L. en II libro XVI del Codice Teodosiano. Alle origini della codificazione in tema di rapporti Chiesa-Stato, Napoli 1985, 20, donde se relaciona con la emperatriz la normativa alusiva a la nueva universidad de la ciudad del Bósforo (CTh.XIV,9,3 del 27 de febrero del 425 y CTh.VI,21,1 del 15 de marzo del mismo año). Incluso se estima que las distintas fuentes que nos informan sobre el carácter y comportamiento de Teodosio II indican que durante su mandato la política desarrollada no es obra exclusiva del emperador, sino fruto de una acción de gobierno inspirada o influenciada por distintos componentes de la corte.

34 PLRE vol. II, 408-409. 
tancio III surgieron desaveniencias con Honorio, al extremo que fue desposeída de su rango, pese a lo cual mantuvo esta consideración en la zona oriental del Imperio. Tras la muerte de Honorio en agosto del 423 y una vez depuesto el usurpador Juan, regresa a Roma y con el apoyo de Teodosio II recupera en el 425 su título de Augusta, actuando como regente de Valentiniano $1 \mathrm{II}^{35}$, que por aquel entonces contaba con seis años. En consecuencia y ante la corta edad del Augustus, la normativa surgida en la pars Occidentis a partir de esa fecha bien pudiera tener como autora a su madre ${ }^{36}$.

Por lo demás en el caso de Constancio III y Gala Placidia vuelve a manifestarse el trato dispar que reciben el Augustus y la Augusta, de forma que pese a toda la problemática que rodea el nombramiento de Constancio III, ya que, como previamente hemos indicado, al parecer no fue reconocido en la pars Orientis, y pese a su brevísimo Augustado (apenas seis meses: de febrero a septiembre del 421$)^{37}$, en el Teodosiano aparece en la inscriptio de cuatro constituciones (CTh.III,16,2; X,10,29; II,27,1; y X,10,31) ${ }^{38}$. En cambio su esposa Gala Placidia que se mantuvo como Augusta casi 30 años (del 421 al 450), no aparece en el encabezamiento de ninguna.

Aún con este trato discriminatorio, no obstante resulta clara la trascendencia política de las mujeres del entorno de los emperadores tardoantiguos en la confección de la ley ${ }^{39}$. Pero no queda aquí su importancia, y de hecho en ocasiones su iniciativa es determinante en el devenir de los acontecimientos. De este modo en Zos.II,11,1 se habla de la decisiva intervención de Fausta para evitar una conspiración auspiciada por su padre Maximiano y contra su esposo Constantino. Ello sin embargo no impide que

35 PLRE vol.II, 889.

36 No obstante signifiquemos que esta normativa no es muy numerosa por cuanto desde la muerte de Honorio existe una clara primacia de la legislación surgida en Oriente. De este modo la última alusión en la compilación teodosiana a una constitución emitida en Occidente data del 24 de marzo del 432 (CTh.VI,23,3). A partir de esta fecha y hasta el cierre de la compilación en el 437 , no volvemos a tener noticias sobre constituciones publicadas en Occidente.

37 PLRE vol. II, 321-325.

38 Precisemos que CTh.X,10,31 se data el 25 de julio del 422, con lo cual o bien la datación es errónea, o bien lo es el encabezamiento de la ley por cuanto Constancio III fallece de enfermedad en septiembre del año anterior. En tal sentido en su edición GotHOFREDUS considera que en la inscriptio de la citada ley tan sólo deben aparecer Honorio y Teodosio II (op.cit., vol. III, 485-486).

Ahora bien, también es posible que el nombre de Constancio III debiera ser incluido en otras leyes emitidas en el 421 . Seria el caso de CTh.II,15,1; XVI,2,45 y IX,24,23 por cuanto todas muestran al mismo destinatario que CTh.X, 10,29 y 30 , y dos de ellas están datadas en la misma fecha, esto es, el 8 de julio del 421. En tal sentido se expresa también GothOFREDUS, estimando oportuna la inclusión de Constancio III en el encabezamiento de todas ellas (op.cit., vol. I, 340-341; vol. VI 1/ VI 2, 99-103; y vol. III, 379).

39 Por supuesto en el futuro parece mantenerse tal tendencia y así por ejemplo Teodora, esposa de Justiniano, será determinante en la normativa del emperador desde dos puntos de vista: como inspiradora de medidas legislativas a favor de la mujer (leyes sobre el matrimonio, el divorcio y el aduiterio) y en temas de carácter general al extremo que Justiniano concederá en ocasiones primacia al consejo de su esposa frente al de sus más estrechos colaboradores, y en el plano publicistico como posible corregente del propio Justiniano (BoniNı, R., Introduzione allo studio di età giustinianea, Bologna 1979, 12). 
en el futuro tenga un trágico final y sea condenada a muerte por el propio Constantino ${ }^{40}$.

Igualmente de decisiva se revela la intervención de Eusebia, esposa de Constancio II, en la designación de Juliano como Caesar. Así en Zos.III,1,2 se dice de ella "mujer de la más alta cultura y cuya inteligencia sobrepasaba la natural en su sexo (véase el juicio de valor de la época sobre la inferioridad femenina), lo induce (a Constancio (I) a tomar una decisión, aconsejándole que nombre césar para las provincias transalpinas a Juliano (...) " ${ }^{41}$. Trascendental también es la intervención de Justina con motivo de la expedición de Teodosio contra Magno Máximo, al extremo que Zósimo la relaciona con el interés que en el emperador despierta por su hija Gala y así se dice Aquélla (Justina) declaró que no se la entregaría (se refiere a su hija Gala) a menos que, emprendiendo la guerra contra Máximo, castigase el asesinato de Graciano y restituyese a Valentiniano el imperio de su padre. Tras conseguir (Teodosio I) desposarla bajo estas condiciones, se entregó por completo a los preparativos de la guerra (Zos.IV,44,4).

Otros elementos que en alusión a las mujeres de la corte formula Zósimo, encajan con el patrón de mujer y la consideración que de ella se tiene en la época. De este modo y en sentido positivo, se hace referencia a su condición de madre y esposa y a su amor por la familia. Por el contrario en sentido negativo son tratados el adulterio y la belleza femenina. Por su parte en el compendio legislativo del Teodosiano se observa que entre los considerados débiles de la sociedad sigue estando la mujer, de manera que no es extraño hallar diversa normativa referente a la protección ofrecida a pupilas y

40 Acerca de las circunstancias que rodean la muerte de Crispo, vid. GUTHRIE, $P$, "The execution of Crispus", Phoenix XX/4 (1996), 325-331. En concreto se desechan los motivos morales y se opta por creer que la muerte de Crispo se debe más a su condición de ilegítimo, ya que siendo hijo de la concubina Minervina, estaria incapacitado para heredar el trono, de modo que Constantino pensando en evitar los problemas y la anarquía que pudieran seguir a su muerte entre el citado Crispo y el resto de sus hijos, decidió eliminarle pese a su manifiesta preparación en el terreno de la administración y el ejército.

En cuanto a la muerte de Fausta se han barajado diversas hipótesis, relacionando con ella las medidas que contra el adulterio promulga Constantino en el año 326 (CTh.IX,7,1-2 y IX,8,1). Sobre el particular, vid. POhlSANDER, Hans A., "Crispus: Briliant Career and Tragic End", Historia XXXIII/1 (1984), 79-106, quien especula con la posibilidad de una relación adúltera bien entre Fausta y alguien de rango inferior en cuyo caso su muerte no estaria relacionada con la de Crispo, o bien entre Fausta y el propio Crispo, quien sería denunciado por ella porque éste no mostraria mucho interés por una mujer 10 años mayor que él o porque le considerase un obstáculo para el futuro de sus hijos (Constantino II, Constante y Constancio II). En cualquier caso las razones de uno y otro asesinato todavia hoy resultan desconocidas.

${ }^{41}$ No es ésta la única ocasión que en la obra de Zósimo resulta determinante el consejo de un miembro femenino de la casa imperial. Asi en alusión a Serena se dice que gracias a su consejo Honorio se persona en Rávena ante la amenaza de Alarico: «Al hablar de esta manera (Honorio) no lo hacia sin embargo, por convencimiento propio, sino siguiendo el consejo de Serena, pues ésta quería que el Emperador habitase en la ciudad más segura a fin de que, si Alarico violaba la paz y atacaba Roma, no se apoderase también de él. Serena en efecto estaba empeñada en salvar al Emperador, ya que en la salvación de éste ponía también su propia seguridad" (Zos. V,30,2)

La propia muerte de Serena se relaciona con otra fémina de la corte: Gala Placidia, y así se considera que su opinión, junto con la del Senado, es tenida en cuenta a la hora de que sea condenada a muerte bajo la acusación de atraer a los bárbaros contra Roma en el asalto a la ciudad por las tropas de Alarico (Zos. V,38,1-4). 
viudas. Al mismo tiempo se regula y se vela igualmente por el decoro y la moral femenina, como acontece con el conjunto de constituciones alusivas a fenómenos como el repudium, el adulterio, la prostitución o las mujeres de la escena ${ }^{42}$.

Respecto a la condición de madre, al decir de Zósimo, puede tener consecuencias positivas o negativas. De este modo el que Crispo fuera hijo de una concubina, tal y como se afirma en Zos.II,20,2, puede provocar que tenga una menor consideración que los otros hijos de Constantino, tal y como se ha señalado en la nota 40 . En cambio ser hijo de madre ligada a la casa imperial, puede legitimar en el trono. De este modo en Zos.II,43,2 se estima que uno de los usurpadores en tiempos del reinado de Constancio II (Nepociano), pretendió su legitimación aludiendo ser hijo de Eutropia, una supuesta hija del emperador Constantino.

Igual de importante se revela el respeto que a los consejos maternos han de prestar los hijos. De este modo Zósimo relaciona el fracaso de la usurpación de Magnencio, con el que desatienda las indicaciones de su madre quien le aconseja que varíe su ruta instantes antes de su final derrota ante las tropas de Constancio II (Zos.II,46,1).

Al mismo tiempo se destaca el amor de las madres por sus hijos y la atención que ponen en el cuidado de sus intereses. El ejemplo más evidente es el de Justina, al reclamar a Teodosio I la deposición del usurpador Magno Máximo y la devolución del trono a su hijo Valentiniano II, para lo cual explota hábilmente la atracción física que por su hija Gala sentiría el emperador oriental (Zos.IV,44,2-4).

42 En cuanto a estas dos últimas cuestiones en la compilación teodosiana hallamos 13 constituciones incluidas en el título 7 del libro XV ("De scaenicis») y fechadas entre el 11 de febrero del 371 y el 8 de febrero del 413, y otras dos en el título 8 del mismo libro ("De lenonibus") y datadas en los reinados de Constancio II y Teodosio II.

En referencia a la mujer de la escena, se afirma que tiene una vida vulgar (CTh. $X V, 7,2$ del 371 ), se ordena que las que sean cristianas y en reverencia de su te, sean apartadas de la escena (CTh.XV, 7,4 del 380 ), no negándoseles una vacatio por dichos motivos, aunque si luego se ven envueltas en asuntos indecorosos (turpes complexiones) y traicionan la religión, regresarán a los espectáculos teatrales y en ellos permanecerán el resto de sus dias (CTh.XV,7,8 del 381). Más aún en CTh.XV,7,12 del 394 se ordena que las actrices mímicas no utilicen en la escena los hábitos que son empleados por la vírgenes consagradas a Dios. En cualquier caso, en CTh.XV,7,13 del 413 finalmente se reconoce que la población gusta de estos espectáculos y por tanto se decreta que las mujeres que hayan abandonado sus obligaciones con la escena, sean llamadas de nuevo a ella. No obstante la que consideramos más significativa de este grupo de constituciones es CTh..XV,7,11 de septiembre del 393 donde se prohíbe a las actrices mimicas y a otras actrices que usen gemas, sedas de color púrpura y textiles dorados, probablemente por ser elementos de la dignidad de los emperadores y las emperatrices. En la ley se precisa que pueden utilizar otros colores y portar oro sin gemas en cuello, brazos y cintura.

Respecto a la prostitución, en CTh.XV,8,1 del 343, se prohibe la venta para la prostitución de mujeres que veneren la religión cristiana, y en CTh.XV,8,2 del 428, se arrebata a los padres y a los domini lenones el derecho de propiedad sobre las hijas o esclavas a las que fuercen a la necessitas de pecar, al extremo que incluso pueden llegar a ser condenados a las minas públicas.

Sobre las otras dos cuestiones (adulterio y divorcio) seguidamente se analizará la normativa emitida por Constantino. 
También puede observarse en la Nueva Historia el amor fraternal de la mujer de la casa imperial. Así se nos dice que al conocerse el asesinato de Valentiniano II, su hermana Gala es presa de un "gran disgusto" y que llena de alboroto el palacio imperial $(Z o s . I V, 55,1)$. En todo caso no es menos cierto que Zósimo deja entrever que en la angustia de la emperatriz también influye el que se encuentre en una corte, la oriental, donde apenas contaria con elementos que le fueran afines. También se alaba la fidelidad, como sucede al abortar Fausta una conspiración urdida contra su esposo Constantino (Zos.II,11,1), lo cual hace más penoso su posterior asesinato.

En cuanto a la consideración negativa y peyorativa de la mujer, encontramos la denuncia del adulterio que puede conducir a la muerte de la adúltera, tal y como indica Zósimo al referirse a las muertes de Crispo y Fausta (Zos.ll,29,2-3). Igual de negativa es estimada la belleza femenina, no por la belleza en sí misma, sino por la atracción que puede despertar en aquellos que teniendo responsabilidades en las tareas de gobierno, las desatienden o descuidan por unas faldas, con el peligro que para la gestión del Estado ello comporta. Exactamente de ello acusa Zósimo a Teodosio I (Zos.IV,44,2$4)^{43}$, y antes que a él, y siguiendo una explicación tradicional, a Marco Antonio por su amor con Cleopatra (Zos. III,32,3).

En la obra legislativa de Teodosio II destacamos la numerosa legislación que en relación con la mujer se promulga en el reinado de Constantino, de un lado por considerar esta producción normativa como la más significativa, aunque por supuesto no la única, y de otro por tratarse de un emperador que se erige en claro punto de referencia para los contextores del Teodosiano ${ }^{44}$. De esta manera y siguiendo un orden cronológico, prontamente, el 1 de abril del 314, hallamos la primera referencia en CTh.IV,12,1 donde se decreta la pérdida de libertad de la mujer libre que por voluntad propia se une a un esclavo (en cambio en el caso de que sea forzada a ello, se ordena que resulte vengada por la severidad de la ley ${ }^{45}$. Seguidamente el 11 de enero del 316 se emite CTh.l,22,1 donde se da protección a la materfamilias cuando se le exija el pago de alguna deuda pública, impidiéndose que sea arrojada de su

43 Señalemos que pese a la pasión que muestra el emperador por Gala, cuando ésta fallece al dar a luz, y siguiendo las noticias de Zósimo, únicamente la “lloró, según el precepto homérico, un dia y a continuación se puso en marcha con el ejército para hacer frente a la guerra (con el usurpador Eugenio)» (Zos.IV,57,3).

${ }_{44}$ No en balde Constantino junto a Teodosio I se erige en el auténtico protagonista de la normativa incluida en el Teodosiano, y de hecho se trata de los dos emperadores de los que mayor número de leyes se seleccionan (respectivamente, 343 y 417 constituciones en 32 y 17 años de reinado). Sumemos a lo dicho que en el propio código se indica que se pretende compilar la legislación surgida en el mundo romano a partir del primero de los emperadores considerado cristiano, recayendo tal honor en Constantino (CTh.I, 1,5 y 6 del 429 y 435 respectivamente). Además de ello en frecuentes ocasiones se alude en la legislación de otros emperadores a la normativa de uno $u$ otro (por ejemplo, CTh.XI,36,14; XVI,8,13; XIV,17,14; XII,3,2; etc.).

45 En enero del año 320 Constantino emite CTh.IV,12,3 matizando lo dicho en el año 314 , de forma que ahora se estipula que la mujer libre que cohabite con un esclavo perteneciente al fisco o al patrimonio imperial no verá afectada su condición juridica, pero los hijos nacidos de tal unión serán considerados ilegítimos y aunque sean libres ocuparán una situación intermedia. El 6 de octubre del 331 nuevamente el emperador ha de referirse al mismo asunto de modo que se recuerda la anterior normativa y se decreta la pérdida de li- 
hogar y arrastrada públicamente por funcionarios de la administración en virtud de la orden de un iudex, y todo ello, y así se dice en la ley, "en consideración de su sexo" (considerato sexu). Más aún en la ley se estipula la pena capital si en el futuro alguien pretende actuar de este modo.

El 4 de diciembre del mismo año se promulga CTh.IX,1,1 donde se ordena que se sometan a las leyes públicas los individuos de clarissima dignitas si, entre otros crímenes, violan o fuerzan a una doncella. Más tarde, el 16 de noviembre del 318 mediante la publicación de CTh.IX,15,1 se condena a la pena capital al parricida, y aunque ciertamente en la ley no se menciona directamente el asesinato de la mujer o de la hija, si se dice que entran bajo la categoría de parricidas los que acaben con la vida de un padre, un hijo o alguien en grado de parentesco («... aut omnino affectionis eius»).

Al año siguiente pertenecen los dos siguientes ejemplos. El 18 de marzo del 319 se fecha el primero de ellos: CTh.IX,21,1, donde nuevamente el legislador formula la distinción existente entre los individuos en función no sólo de su status legal, sino también de su sexo. A partir de ahí a los falsificadores de moneda se les aplicarán distintas penas ( «... poenam pro discretione sexus et condicionis suae diversitate sustineat"). Más adelante, el 16 de octubre del 319 , se emite CTh.III,5,2 donde se concede a la mujer comprometida en matrimonio la devolución de su dote si su prometido rompe unilateralmente el compromiso. Si por el contrario la ruptura es debida a la mujer o a la persona de la que ella depende, todas las donaciones efectuadas permanecerán en posesión del hombre comprometido.

El 31 de enero del 320 se publica CTh.VIII,16,1 que viene a derogar la normativa existente desde los días de Augusto y que ciertamente perjudicaba los intereses de los célibes. A partir de ahora estarán equiparados a todos los efectos con los casados, extendiéndose esta equiparación también a las mujeres que opten por el celibato ${ }^{46}$. El 1 de abril de ese mismo año en CTh.IX,24,1 encontramos un nuevo juicio de valor sobre la figura femenina de manera que, en esta ley que pretende proteger a las puellae de ser violentadas, se dice de ellas que por la volubilidad y la inconstancia propias de su sexo ( «... propter vitium levitatis et sexus mobilitatem...») pueden propiciar la violación. En relación con ello se dictamina que se arroje plomo fundi-

bertad de la mujer que cohabita con un esclavo. Dicho de otro modo, por la reiteración en la normativa parece evidente su incumplimiento.

De otra parte recordemos que la preocupación por la familia y por cuestiones que la afectan como puedan ser el matrimonio o el adulterio, existe desde tiempos anteriores a Constantino, y así por ejemplo contamos con la legislación que sobre el particular produce el primero de los emperadores romanos, Cayo Octavio Aurgusto: la lex lulia de maritandis ordinibus y la lex Papia Poppaea. Sobre la legislación constantiniana relativa a la familia, vid. GRuBBS, J. E., "Constantine and Imperial Legislation on the Family", The Theodosian Code, London 1993, 120-143, donde también se trata el posible influjo que sobre su legislación pudiera haber ejercido el cristianismo.

46 Acerca de la legislación constantiniana que deroga leyes augústeas, vid. Spagnuolo VIGorita, T,, "Inminentes legum terrores. L'abrogazione delle leggi caducarie augustee in età costantiniana", Atti deII'Accademia Romaristica Costantiniana, VII Convegno Internazionale, Perugia 1988, 251-267. 
do en las bocas de las nodrizas por cuyo consejo y persuasión se llega a situaciones de este tipo. Igualmente se establece que se castigue a la puella con la misma severidad que se hace con el raptor si dio su consentimiento en la unión. Y por último se establece el mismo castigo para los que participen en este crimen sin distinción de sexo, y en el caso de que uno de los implicados sea de condición servil, que sea quemado igualmente sin distinción de sexo.

El 9 de abril del 321 de nuevo hallamos el juicio moral sobre el carácter femenino y de este modo en CTh.II,17,1 al considerarse los derechos que los adolescentes tienen para dirigir sus patrimonios, se hace hincapié que en el caso de las mujeres se tendrá en cuenta su carácter honesto, su inteligencia y su buena reputación, alabándose su timidez y su pudor ${ }^{47}$.

El trato discriminatorio a la mujer nuevamente se manifiesta cuando a cuestiones testamentarias se procede, y asi sucede en CTh.V,1,1 del 19 de mayo del 321, donde se explicita que las madres no tienen los mismos derechos que los padres en las propiedades de los hijos, si bien se estipula ahora que un tercio de las mismas recaiga en ellas. Anteriormente, el 27 de febrero de ese año, se ha publicado CTh.IX,42,1 donde se ordena que en el caso de herencias que legalmente llegan al control de la mujer antes de que su esposo o su padre se vean acusados y condenados por algún crimen, se conserven íntegramente bajo el control de las esposas o hijas.

El siguiente caso data del 9 de febrero del 322: CTh.IX,1,3, donde se indica que resulta evidente y manifiesto que en el terreno de la ley la mujer no tiene la facultad de continuar asuntos públicos criminales salvo en ciertos casos, esto es, cuando se produzca una iniuria sobre ellas o sobre miembros de su familia. Por lo demás, apenas pueden formular acusaciones.

Tras un silencio de cuatro años en la normativa, en el año 326 hallamos la que sin duda es la legislación constantiniana más conocida en alusión a la mujer puesto que se la ha relacionado con el turbulento episodio del doble asesinato de Fausta y Crispo ${ }^{48}$. Nos referimos en concreto a legislación sobre el adulterio. De este modo el 3 de febrero de ese año se emite CTh.IX,7,1 donde se condena el adulterio femenino, precisándose que la pudicitia ha de exigirse sólo a aquellas mujeres que están obligadas por los vínculos de la ley, no a las que son de insignificante status. El 25 de abril, por medio de CTh.IX,7,2 se afirma que el adulterio es un crimen público y se precisa a quién se concede el derecho de acusación, recayendo principalmente en la figura del marido. Poco antes, el 4 de abril se ha publicado CTh.IX,8,1 donde se hace hincapié en la obligación que los tutores tienen de mantener la virginidad de sus pupilas, y en el supuesto caso que la pérdida

47 «... sed eas, quas morum honestas mentisque soliertia, quas certa fama commendat. Has vero propter pudorem ac verecundiam in coetu publico demonstrati testibus non cogimus ...".

48 Vid. nota 40. 
de la castitas sea cosa del tutor, será deportado y su propiedad confiscada. En fin, el 29 de mayo se emite CTh.IX,9,1 donde se condena a la pena capital a la mujer libre que tenga un amante esclavo, concediéndose a todo el mundo la facultad para denunciarlo.

Hasta el 4 de mayo del 329 no hallamos un nuevo ejemplo de normativa dedicada a la mujer. En concreto se trata de CTh.IX,21,4 donde al referirse a la falsificación de moneda se estipula que en el caso de pupilos y viudas se tendrá una indulgencia especial de forma que no pierdan sus propiedades si fue en ellas y sin su consentimiento donde se procedió a la falsificación.

A continuación, el 29 de abril del 330 se publica CTh.III,5,3 donde se socorre a las mujeres para que tras el cese del afecto marital no pierdan aquellas propiedades que se les confirieron y que no fueron registradas en las actas por el marido.

El año siguiente hallamos otra normativa constantiniana no menos famosa, la que se refiere al divorcio. De este modo en el 331 se emite CTh.III,16,1 donde se establecen las causas que pueden esgrimirse para proceder a una notificación de repudium, impidiéndose a la mujer formularla por iniciativa propia, de forma que tan sólo podrá efectuarla alegando que su esposo es homicida vel medicamentarius vel sepulchrorum dissolutor, caso contrario la notificación no será atendida, más aún será deportada a una isla. En cambio el hombre puede alegar que su esposa es adúltera, bruja o alcahueta ("moecha vel medicamentaria vel conciliatrix»). Si la acusación es infundada, perderá la dote aportada por ella ${ }^{49}$.

La última significativa mención en legislación de Constantino a la mujer es la que se formula el 17 de junio del 334 en CTh.1,22,1 donde se habla de la lenitas del emperador para con pupilos, viudas y personas enfermas, estimadas todas ellas de fortuna miserable. En concreto en la ley se alude al momento en el que hayan de presentarse en un proceso tras ser convocados por un juez en otra provincia.

Resumiendo, a nivel institucional, público o privado, resulta evidente el trato discriminatorio hacia la mujer y su inferioridad de condiciones, aparte de la existencia de una serie de prejuicios éticos y morales que aparecen de forma clara tanto en la legislación como en la obra de Zósimo. Con todo y como hemos analizado, el papel que en la práctica juegan los miembros femeninos de la corte es bastante superior a lo que oficialmente se dice de ellas. De otra parte el que frecuentemente se mencione a la mujer en la normativa tardoimperial no hace sino confirmarnos que comienza a cobrar un creciente protagonismo.

49 Sobre el contexto en el que se formularia la constitución vid. VENTURINI, C., "La ripudianda (in margine a CTh.III, 16,1)", Atti dell'Accademia Romanistica Costantiniana, VIII Convegno Internazionale, Perugia $1990,343-36 \%$. 